University of Nebraska - Lincoln

DigitalCommons@University of Nebraska - Lincoln

NASA Publications

National Aeronautics and Space Administration

2014

Ice cloud detection from AMSU-A, MHS, and HIRS satellite instruments inferred by cloud profiling radar

Tanvir Islam

NOAA/NESDIS Center for Satellite Applications and Research, College Park, MD

Prashant K. Srivastava

University of Bristol, Bristol, UK

Qiang Dai

University of Bristol, Bristol, UK

Manika Gupta

NASA Goddard Space Flight Center, Greenbelt, MD

Follow this and additional works at: http://digitalcommons.unl.edu/nasapub

Islam, Tanvir; Srivastava, Prashant K.; Dai, Qiang; and Gupta, Manika, "Ice cloud detection from AMSU-A, MHS, and HIRS satellite instruments inferred by cloud profiling radar" (2014). NASA Publications. 175.

http://digitalcommons.unl.edu/nasapub/175

This Article is brought to you for free and open access by the National Aeronautics and Space Administration at DigitalCommons@University of Nebraska - Lincoln. It has been accepted for inclusion in NASA Publications by an authorized administrator of DigitalCommons@University of Nebraska - Lincoln. 


\title{
Ice cloud detection from AMSU-A, MHS, and HIRS satellite instruments inferred by cloud profiling radar
}

\author{
Tanvir Islam ${ }^{\mathrm{a}, \mathrm{b}, \mathrm{c} *}$, Prashant K. Srivastava ${ }^{\mathrm{c}, \mathrm{d}, \mathrm{e}}$, Qiang Dai ${ }^{\mathrm{c}}$, and Manika Gupta ${ }^{\mathrm{d}, \mathrm{f}}$ \\ ${ }^{a}$ NOAA/NESDIS Center for Satellite Applications and Research, College Park, MD, USA; \\ ${ }^{b}$ Cooperative Institute for Research in the Atmosphere, Colorado State University, Fort Collins, CO, \\ USA; ${ }^{c}$ Department of Civil Engineering, University of Bristol, Bristol, UK; ${ }^{d}$ NASA Goddard Space \\ Flight Center, Greenbelt, MD, USA; ${ }^{e}$ Earth System Science Interdisciplinary Center, University of \\ Maryland, College Park, MD, USA; ${ }^{f}$ Universities Space Research Association, Columbia, MD, USA
}

(Received 1 July 2014; accepted 16 November 2014)

\begin{abstract}
An algorithm for ice cloud detection aided by support vector machine (AID-SVM) is presented. The AID-SVM algorithm is applied and tested for the Advanced Microwave Sounding Unit-A, microwave humidity sounder (MHS), and high resolution infrared radiation sounder (HIRS) instruments onboard NOAA-19 satellite. The algorithm is based on satellite brightness temperature measurements and developed as well as validated by using collocated ice/no-ice cloud information acquired from the CloudSat cloud-profiling radar. The algorithm is tested over both ocean and land surfaces. Overall, the results exhibit very promising potential to acquire ice/no-ice cloud information using the passive satellite sensors. It is found that infrared satellite sensor such as HIRS is more efficient in detecting ice clouds than the counterpart microwave satellite sensors. Furthermore, the combined measurements using microwave/infrared synergy perform no better than the infrared-only measurements.
\end{abstract}

\section{Introduction}

The detection of ice clouds is imperative for a variety of reasons within the atmospheric sciences domain. First, the ice clouds carry significant role in global atmosphere, mainly, because of its radiative influence on earth's energy balance (Koop 2013; Yamada and Satoh 2013; Gao, Li, and Zhou 2014). Second, ice clouds regulate the forecasting applications and have an influence on climate change (Delanoe et al. 2011; Protat et al. 2011; Jin et al. 2014). Better detection of ice clouds will lead to better weather and climate forecasts. Third, accurate detection of ice clouds is a necessary step in satellite remote sensing, and subsequently, the retrieval of geophysical parameters as ice clouds can impact the quality of such retrieval (Østby, Schuler, and Westermann 2014).

Over the past years, a wide range of satellite instruments has been deployed to enable the observations of global coverage of ice clouds. Given the importance of ice cloud properties in the Earth's energy budget, such satellite studies of ice clouds continue to be an area of active research. Particularly, progresses have been made on both microwave (MW) and infrared (IR) remote sensing-based cloud detection algorithms (Inoue et al. 2010; Sreerekha, Doherty, and English 2010; Wind et al. 2010; He 2011; Yoo and Li 2012; Hutchison, Iisager, and Mahoney 2013; Millán et al. 2013). Generally speaking, most of the algorithms employ threshold-based criteria to distinguish between cloudy and clear pixels. Despite the progress, it is also to be remembered that there are intrinsic limitations to the passive satellite observations for ice cloud studies (Liu et al. 2010). Passive satellite sensors cannot sense the full vertical structure

*Corresponding author. Email: tanvir.islam@noaa.gov or tanvir.islam@msn.com 
of a storm as active sensors can do. Consequently, in passive remote sensing-based ice cloud algorithms, vertical cloud homogeneity are assumed, which may lead to erratic outputs.

To overcome the above limitations, CloudSat satellite carrying a millimeter wavelength cloud profiling radar (CPR) was launched to join the A-train satellite constellation in 2006 (Stephens et al. 2002). The primary purpose of the CloudSat satellite is to study clouds and precipitation from space. In fact, cloud radar can potentially detect those sensitive clouds, which remain undetected by passive satellite measurements. However, CloudSat's area coverage is limited. As a fact, in addition to the cloud radar, the use of passive satellite measurements is essential for enhancing the temporal and spatial resolutions of ice cloud products.

In this study, we propose an ice cloud detection algorithm for passive satellite sensors at MW/IR frequencies. The proposed algorithm will be based on support vector machine (SVM). The algorithm, hereinafter named as an algorithm for ice cloud detection aided by SVM (AID-SVM), will be trained in such a way that the passive remote sensing-based output is in consistent with the CloudSat radar ice/no-ice cloud observations. The combined use of MW/IR observations will also be investigated in determining whether they are able to improve the detection capability.

\section{Data}

The reference radar data sets used in this work are from the CPR-derived radar-only ice water path (IWP) information stored in 2B-CWC-RO product according to the algorithm described in Austin, Heymsfield, and Stephens (2009). In contrast, the passive satellite data are from the Advanced Microwave Sounding Unit (AMSU)-A, microwave humidity sounder (MHS), and high resolution infrared radiation sounder (HIRS) instruments onboard NOAA-19 satellite (see Tables 1-2 for the radiometric characteristics). It is to be noted that the former two sensors are MW radiometers, whereas the later sensor gathers visible and IR radiometric observations. The AMSU-A measures the MW radiation with 15 radiometric channels between 23 and $50 \mathrm{GHz}$ using cross-track scanning strategy. Similar to the AMSU-A, MHS is a five-channel cross-track radiometer with three channels in the water vapour absorption line $(183.31 \mathrm{GHz})$ along with two window channels ( 89 and $150 \mathrm{GHz}$ ). On the other hand, the HIRS instrument is operated in 20 channels, including 1 visible and 19 IR channels.

Table 1. Radiometric characteristics of the AMSU-A (1-15) and MHS (16-20) channels.

\begin{tabular}{llccc}
\hline \multicolumn{1}{c}{$\begin{array}{c}\text { Frequency } \\
\text { Channel number }\end{array}$} & \multicolumn{1}{c}{ Polarization } & Number of bands & Instrument sensitivity (K) \\
\hline 1 & 23.8 & $\mathrm{~V}$ & 1 & 0.30 \\
2 & 31.4 & $\mathrm{~V}$ & 1 & 0.30 \\
3 & 50.3 & $\mathrm{~V}$ & 1 & 0.40 \\
4 & 52.8 & $\mathrm{~V}$ & 1 & 0.25 \\
5 & $53.596 \pm 0.115$ & $\mathrm{H}$ & 2 & 0.25 \\
6 & 54.4 & $\mathrm{H}$ & 1 & 0.25 \\
7 & 54.94 & $\mathrm{~V}$ & 1 & 0.25 \\
8 & 55.5 & $\mathrm{H}$ & 1 & 0.25 \\
9 & 57.290 & $\mathrm{H}$ & 1 & 0.25 \\
10 & $57.290 \pm 0.217$ & $\mathrm{H}$ & 2 & 0.40 \\
11 & $57.290 \pm 0.3222 \pm 0.048$ & $\mathrm{H}$ & 4 & 0.40 \\
12 & $57.290 \pm 0.3222 \pm 0.022$ & $\mathrm{H}$ & 4 & 0.60 \\
13 & $57.290 \pm 0.3222 \pm 0.010$ & $\mathrm{H}$ & 4 & 0.80 \\
14 & $57.290 \pm 0.322 \pm \pm 0.0045$ & $\mathrm{H}$ & 4 & 1.20 \\
15 & 89.0 & $\mathrm{~V}$ & 1 & 0.50 \\
16 & 89.0 & $\mathrm{~V}$ & 1 & 0.22 \\
17 & 157.0 & $\mathrm{~V}$ & 1 & 0.34 \\
18 & $183.311 \pm 1.00$ & $\mathrm{H}$ & 2 & 0.51 \\
19 & $183.311 \pm 3.00$ & $\mathrm{H}$ & 2 & 0.40 \\
20 & 190.311 & $\mathrm{~V}$ & 1 & 0.46 \\
\hline
\end{tabular}


Table 2. Radiometric characteristics of the HIRS channels.

\begin{tabular}{lccccc}
\hline Channel & $\begin{array}{c}\text { Centre wave } \\
\text { number }\left(\mathrm{cm}^{-1}\right)\end{array}$ & $\begin{array}{c}\text { Centre } \\
\text { frequency } \\
(\mathrm{mm})\end{array}$ & $\begin{array}{c}\text { Half } \\
\text { bandwidth } \\
\left(\mathrm{cm}^{-1}\right)\end{array}$ & $\begin{array}{c}\text { Anticipated } \\
\text { maximum scene } \\
\text { temperature }(\mathrm{K})\end{array}$ & $\begin{array}{c}\text { Specified NEDN }(\mathrm{mW} / \\
\left.\mathrm{m}^{2} / \mathrm{sterad}^{-1} \mathrm{~cm}^{-1}\right)\end{array}$ \\
\hline 1 & $668.5 \pm 1.3$ & 14.959 & $3.0+1 /-0.5$ & 280 & 3.00 \\
2 & $680.0 \pm 1.8$ & 14.706 & $10.0+4 /-1$ & 265 & 0.67 \\
3 & $690.0 \pm 1.8$ & 14.493 & $12.0+6 /-0$ & 240 & 0.50 \\
4 & $703.0 \pm 1.8$ & 14.225 & $16.0+4 /-2$ & 250 & 0.31 \\
5 & $716.0 \pm 1.8$ & 13.966 & $16.0+4 /-2$ & 265 & 0.21 \\
6 & $733.0 \pm 1.8$ & 13.643 & $16.0+4 /-2$ & 280 & 0.24 \\
7 & $749.0 \pm 1.8$ & 13.351 & $16.0+4 /-2$ & 290 & 0.20 \\
8 & $900.0 \pm 2.7$ & 11.111 & $35.0 \pm 5.0$ & 330 & 0.10 \\
9 & $1030.0 \pm 4.0$ & 9.709 & $25.0 \pm 3.0$ & 270 & 0.15 \\
10 & $802.0 \pm 2.0$ & 12.469 & $16.0+4 /-2$ & 300 & 0.15 \\
11 & $1365.0 \pm 5.0$ & 7.326 & $40.0 \pm 5.0$ & 275 & 0.20 \\
12 & $1533.0+2 /-6$ & 6.523 & $55.0 \pm 5.0$ & 255 & 0.20 \\
13 & $2188.0 \pm 4.4$ & 4.570 & $23.0 \pm 3.0$ & 300 & 0.006 \\
14 & $2210.0 \pm 4.4$ & 4.525 & $23.0 \pm 3.0$ & 290 & 0.003 \\
15 & $2235.0 \pm 4.4$ & 4.474 & $23.0 \pm 3.0$ & 280 & 0.004 \\
16 & $2245.0 \pm 4.4$ & 4.454 & $23.0 \pm 3.0$ & 270 & 0.004 \\
17 & $2420.0 \pm 4.0$ & 4.132 & $28.0 \pm 3.0$ & 330 & 0.002 \\
18 & $2515.0 \pm 5.0$ & 3.976 & $35.0 \pm 5.0$ & 340 & 0.002 \\
19 & $2660.0 \pm 9.5$ & 3.759 & $100.0 \pm 15.0$ & 340 & 0.001 \\
20 & $14,500 \pm 220$ & 0.690 & $1000 \pm 150.0$ & $100 \%$ Albedo. & $0.10 \%$ Albedo \\
\hline
\end{tabular}

To develop the ice cloud detection algorithms for passive satellite radiometers, that will be consistent with the CloudSat ice cloud detection, it requires bringing the radiometric and CloudSat ice cloud information in the same domain. Therefore, for the sake of analysis, a testbed database is constructed comprising of radiometric and CPR IWP collocation samples collected from a wide range of meteorological events, according to Holl et al. (2010). The collocation database is restricted to latitudes within $25^{\circ}$ of the equator. This is mainly done for minimizing the radiometric scattering coming from the surface. Over the tropics, the atmosphere is very humid. The band of extreme water vapour concentrations would inhibit the radiometers to receive signals from the surface. Further, the collocation database is subdivided into two groups to form calibration and validation data sets, respectively, for training and testing purpose.

\section{Detection algorithm}

Machine learning algorithms have received increasing interest in recent years within the remote sensing community (Islam, Rico-Ramirez, and Han 2012; Islam et al. 2013; Srivastava, Han, Rico-Ramirez, et al. 2013; Islam, Srivastava, et al. 2014). In this study, the proposed ice cloud detection algorithm is based on a machine learning algorithm, the SVM (Srivastava et al. 2012; Srivastava, Han, Ramirez, et al. 2013), in which the inputs are the radiometric brightness temperatures $\left(T_{\mathrm{B}}\right)$, whereas the output is the ice/no-ice cloud properties.

Theoretically, our classification is a supervised binary classification problem. Let us consider the training set consists of $N$ vector samples from a $d$-dimensional feature space, where $x_{i} \in \Re^{d}(i=1,2, \ldots, N)$. For each vector $x_{i}$, a target $y_{i} \in\{-1,1\}$ is given. If the two classes are linearly separable, it would be straightforward to find a hyperplane between two classes defined by a vector $\mathbf{w} \in \Re^{\mathrm{d}}$ and a bias $b \in \Re$. The membership decision rule is based on the signum function $\operatorname{sgn}[f(x)]$ :

$$
f(x)=\mathbf{w} \cdot \mathbf{x}+b
$$

where $f(x)$ denotes the discriminant function associated with the hyperplane. The $\mathrm{w}$ and $b$ are estimate in such a way that 


$$
y_{i}\left(\mathbf{w} \cdot x_{i}+b\right)>0, \quad i=1,2, . ., N
$$

The optimal hyperplane is determined by maximizing the separating margin such that

$$
\min _{i=1,2, \ldots, N} y_{i}\left(\mathbf{w} \cdot x_{i}+b\right) \geq 1
$$

The above linearly constrained optimization problem can be formulated using a Lagrangian function:

$$
\max _{\alpha} \sum_{i=1}^{N} \alpha_{i}-\frac{1}{2} \sum_{i, j=1}^{N} \alpha_{i} \alpha_{j} y_{i} y_{j} K\left(x_{i}, x_{j}\right)
$$

where

$$
\sum_{i=1}^{N} \alpha_{i} y_{i}=0
$$

and

$$
\alpha_{i} \geq 0, \quad i=1,2, \ldots, N
$$

where $\alpha$ is the vector of Lagrange multipliers, which can be obtained using quadratic programming methods. Consequently, the discriminant function is formed as

$$
f(x)=\sum_{i \in S} \alpha_{i} y_{i}\left(x_{i} \cdot x\right)+b
$$

where $S$ is the subset of indices corresponding to non-zero $\alpha_{i}$ 's. These indices are known as support vectors.

In the case of linearly non-separable data, a cost function is minimized using margin maximization and error minimization terms:

$$
\Psi(\mathbf{w}, \xi)=\frac{1}{2}\|\mathbf{w}\|^{2}+C \sum_{i=1}^{N} \xi_{i}
$$

where the $\xi_{i}$ are known as slack variables and $C$ as the penalty parameter. The minimization of the above cost function is under the following constrains:

$$
y_{i}\left(\mathbf{w} \cdot x_{i}+b\right)>1-\xi_{i}, \quad i=1,2, . ., N
$$

and

$$
\xi_{i} \geq 0, \quad i=1,2, . ., N
$$

For further improving the separation, a Kernel function can be introduced. However, in this study, a linear SVM is implemented. The penalty parameter $C$ is taken as 1 . It is important to stress out that the minimum detectable cloud reflectivity by the CPR is around $-26 \mathrm{dBZ}$, leading to an IWP detection limit of $1 \mathrm{~g} \mathrm{~m}^{-2}$ (Austin, Heymsfield, and Stephens 2009; Holl et al. 2010). Considering this, a threshold of $1 \mathrm{~g} \mathrm{~m}^{-2}$ has been taken as the criteria for the separation of ice/no-ice cloud information, while training the AID-SVM. Five different sensor combinations have been investigated as the input measurements to the AID-SVM algorithm: (1) AMSU-A, (2) MHS, (3) HIRS, (4) AMSU-A + MHS, and (5) AMSU-A + MHS + HIRS radiometric $T_{\mathrm{B}}$ measurements. 


\section{Results and discussions}

Before providing the performance of the proposed AID-SVM algorithm here, we investigate the sensitivity of $T_{\mathrm{B}}$ measurements to ice/no-ice cloud information. As such, a parallel coordinate plot is constructed comprising brightness temperature measurements as input vectors in Figure 1. The significance of parallel coordinate plot is that it can make data visualization easier and comparable for a large number of variables together. Furthermore, informative investigation of higher-dimensional relationships between the variables can be made. In this plot, the horizontal axis signifies the coordinate, and the vertical axis signifies the values. That means, first 15 coordinates are related to 15 AMSU-A channels, followed by 5 MHS and 20 HIRS channels. From the parallel coordinates plot, it can be seen that the ice cloud distributions for the HIRS channels 24-39 are significantly different from the noice cloud distributions. This implies that these input measurements are excellent options for ice cloud detection. The MHS channels (16-20) also carry some good skills to classify ice/ no-ice cloud information, as the figure suggests. Nevertheless, the distribution margins are somewhat narrower for the AMSU-A coordinates.

For more detailed understanding, Figures 2 and 3 give the probability density function (PDF) estimate of brightness temperatures for ice and no-ice cloud pixels. Figure 2 is for the AMSU-A/MHS channels, whereas Figure 3 is for the HIRS channels. The PDFs are constructed for ocean surface only by considering the data sets from calibration database. The overlaps between the distributions of ice/no-ice clouds are evident for all the channels, either in AMSU-A or in MHS measurements. This implies that no particular frequency is capable of detecting ice clouds perfectly. However, there are some distribution differences between ice/ no-ice cloud pixels, in some channels. It is to be noted that the AMSU-A channels 3-14 near oxygen absorption band $(60 \mathrm{GHz})$ are primarily designed to measure atmospheric temperature profiles. On the other hand, AMSU-A/MHS channels 1-2, some other window channels near $89 \mathrm{GHz}$ (15-16), along with ice scattering channels near $183 \mathrm{GHz}(18-20)$ are primarily responsible for measuring cloud and surface properties. Such interpretation can clearly be made from Figure 2. It can be seen that the distribution difference is more pronounced for the cloud sensitive channels than the temperature sounding channels. On the other hand, a good distribution difference exists for the HIRS measurements in channels 4-20 (Figure 3).

Overall, based on the parallel coordinate and histogram plots, one should anticipate that HIRS will have better skills in detecting ice/no-ice cloud information than the AMSU-A instrument. In the latter section, we will be scrutinizing, if this is the case. We will also investigate whether the synergistic MW/IR measurements would improve the results in detecting the ice clouds than either the MW or IR measurements on their own. As a reference, in Figure 4, we plot the bivariate histogram distribution of $T_{\mathrm{B}}$ between MHS $183 \pm 3 \mathrm{GHz}$ and HIRS $12.47 \mu \mathrm{m}$ for ice
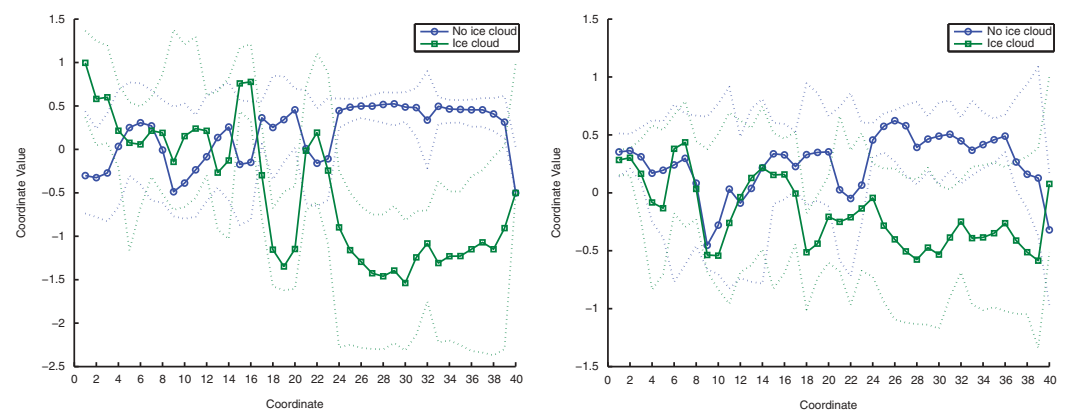

Figure 1. Parallel coordinate plot of brightness temperature measurements for no-ice cloud and ice cloud pixels: ocean (left) and land (right). The coordinates 1-15 represent the AMSU-A channels, followed by the 5 MHS channels, and the 20 HIRS channels. The median and quartiles $(25 \%$ and $75 \%$ points) are also shown as dotted outlines. 


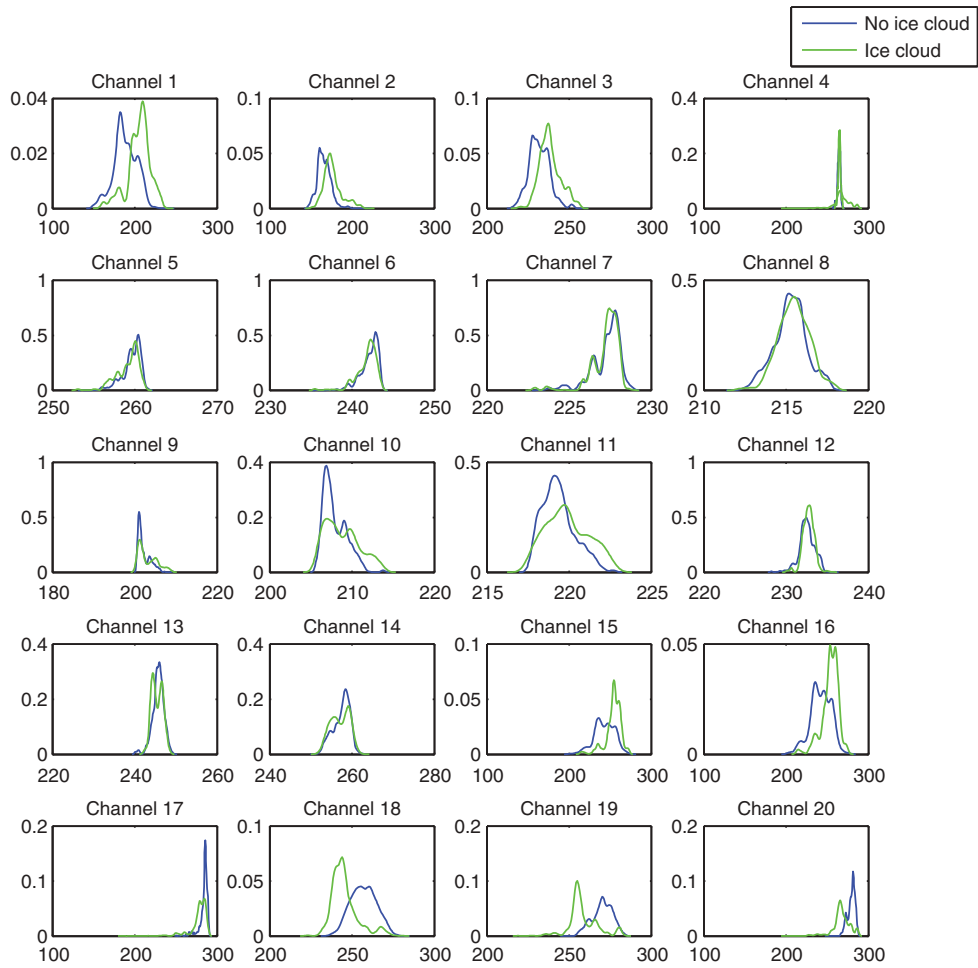

Figure 2. PDF histograms of brightness temperature measurements $(K)$ for the AMSU-A (1-15) and MHS (16-20) channels.

and no-ice cloud pixels. The differences between the distributions are somewhat noticeable. This gives us confidence that both MW and IR measurements will be able to detect ice clouds.

Table 3 summarizes the standard categorical and verification scores of ice cloud detection for the AMSU-A, MHS, HIRS, AMSU-A + MHS, and AMSU-A + MHS + HIRS sensor combinations in comparison with CloudSat CPR observations (using $1 \mathrm{~g} \mathrm{~m}^{-2}$ as detection threshold). The scores are computed using the AID-SVM model applied to the validation database. The following categorical scores are used for the assessment - accuracy, frequency bias, probability of detection, false alarm ratio, probability of false detection, success ratio, critical success index, equitable threat score, Hansen-Kuipers discriminant, odds ratio, and Yule's Q. The basis of the categorical scores is a contingency table, tabulating the agreement and disagreement between the forecast and observations data sets. More information regarding the calculation of the scores can be found in Islam et al. (2012) and Islam, Rico-Ramirez, et al. (2014).

Overall, the categorical scores obtained by the AID-SVM model are very promising. However, the ability to capture accurate ice cloud pixels is rather sensor-dependent. It can be seen that the IR sensor HIRS performs better than the MW instruments AMSU-A and MHS. For instance, over the ocean, the CSI is calculated as 0.68 by the HIRS instrument, whereas, by using the AMSU-A and MHS sensors, respectively, the CSI scores are only 0.32 and 0.45 . Similar conclusions can be made based on other categorical scores. Besides, as indicated by the categorical scores, this is also true over the land surface. Of course, the scores are somewhat decreased over land from the ocean surface, most likely because of non-uniform emissivity of the land surface, which is to be expected. As an example, the CSI score is reduced from 0.68 (ocean) to 0.59 (land) for the HIRS sensor-based ice cloud detection. It is not unexpected that the HIRS sensor outperforms the counterpart MW sensors in detecting ice clouds. The measurements at IR channels are known to be strongly sensitive to thin ice clouds, 


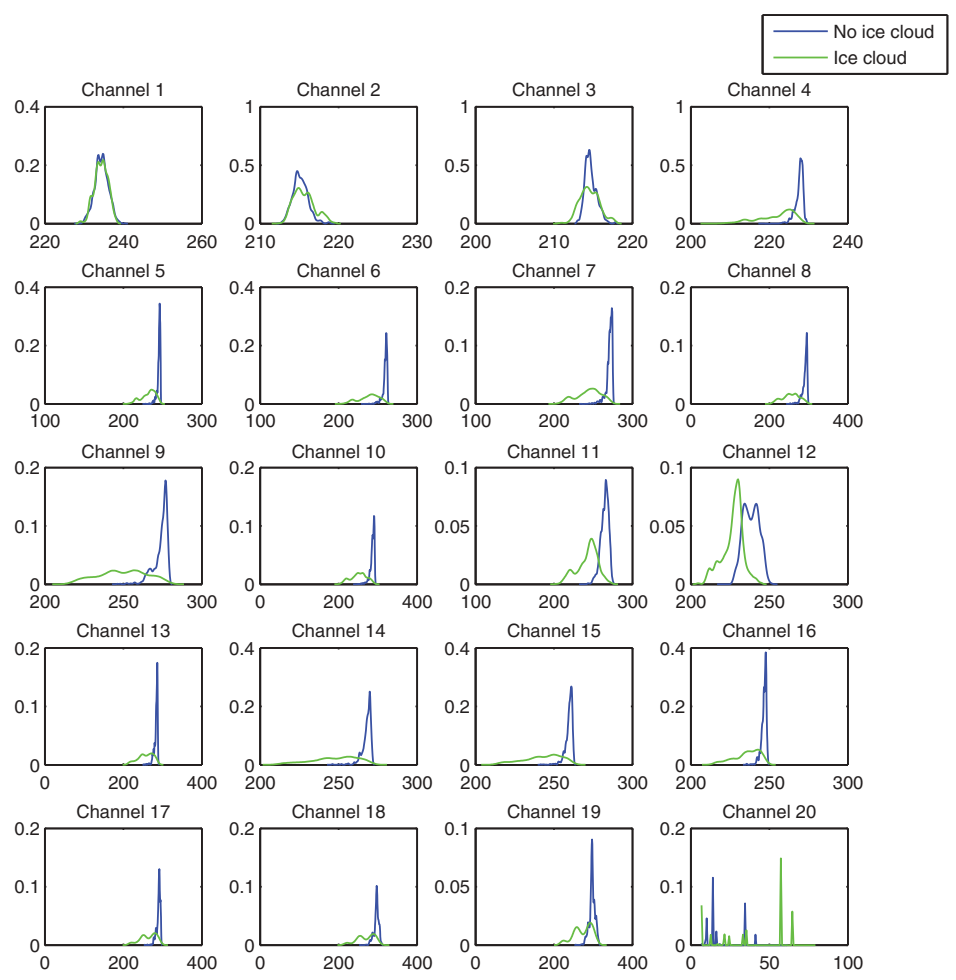

Figure 3. PDF histograms of brightness temperature measurements $(K)$ for the HIRS channels.
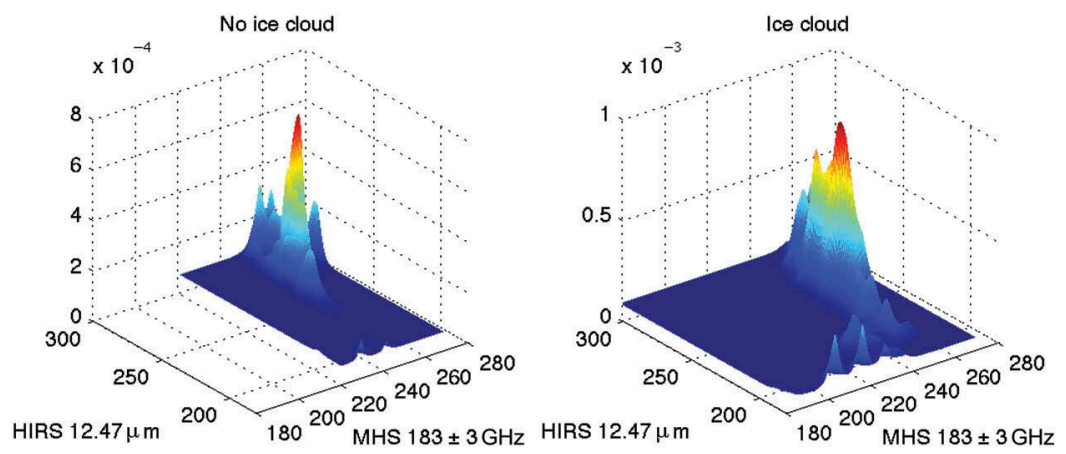

Figure 4. The bivariate histograms of brightness temperature measurements $(K)$ between MHS $183 \pm 3 \mathrm{GHz}$ and HIRS $12.49 \mu \mathrm{m}$ channels: no ice cloud (left) and ice cloud conditions (right).

as reported by many authors (Aires et al. 2011; Stein, Delanoë, and Hogan 2011; Kahn et al. 2014). Therefore, the information content obtained from IR-based measurements can add valuable skills towards ice cloud detection. In contrast, in comparison to IR observations, MW measurements are somewhat less sensitive to thin ice clouds. That is why the AMSU-A and MHS are found to be less skillful for ice cloud detection than the HIRS measurements. Nonetheless, MW measurements have the capability of propagating through the clouds, whereas IR measurements are mainly sensitive to the radiation emitted or scattered from top of the atmosphere. As such, the MW measurements are better capable of sensing the total cloud layer information, thus providing better retrieval of cloud intensity instead (e.g., cloud water contents) than the detection. One more important point to note is that the MHS has better detection capability than AMSU-A instrument, as the table demonstrates. This is mainly 


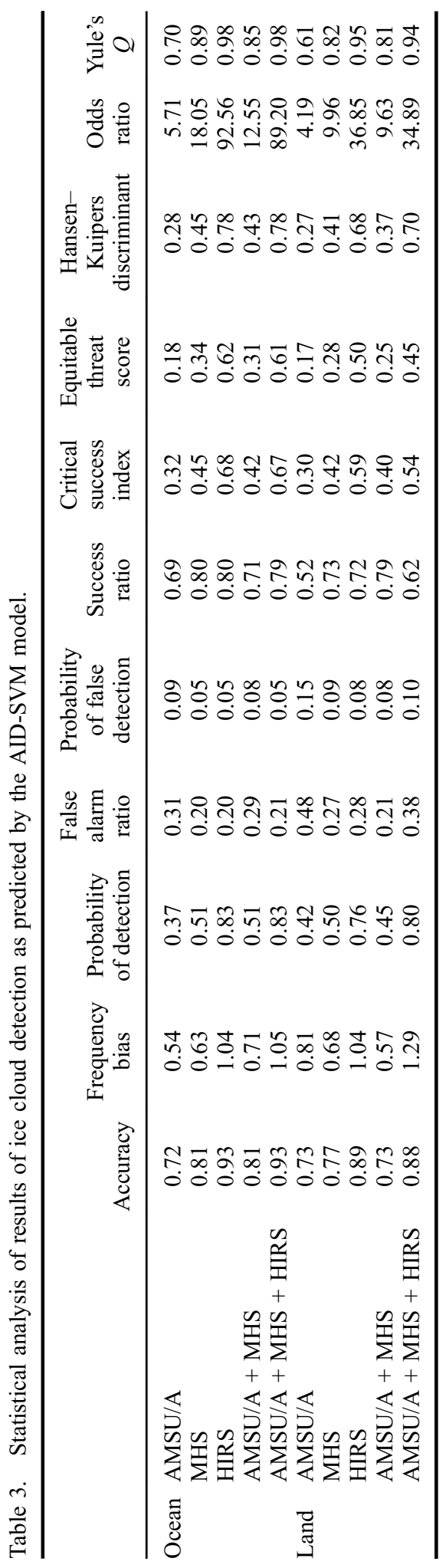


because the scattering phenomenon on ice particles is more dominant at higher frequencies (MHS channels) than at lower frequencies (AMSU-A channels). At lower frequencies, more specifically, below $80 \mathrm{GHz}$, MW radiation is less impacted by the occurrence of ice clouds. The lower frequency measurements are mainly exposed to emission and absorption by liquid clouds. According to our results from Table 3, it is also to be noted that the synergistic MW/IR measurements perform no better than the IR-only measurements. In fact, the relative performance between the HIRS only and AMSU-A + MHS + HIRS combination is comparable.

\section{Summary}

In this article, a new ice detection algorithm (AID-SVM) is introduced for the AMSU-A, MHS, and HIRS passive satellite sensors. The algorithm is based on SVM and uses only satellite brightness temperature measurements as input vectors. The proposed AID-SVM algorithm is complemented by CloudSat CPR ice cloud observations, which are collocated to the passive satellite sensors to calibrate as well as validate the algorithm. The algorithm is found to perform reasonably well in positively identifying ice clouds over both ocean and land surfaces. In particular, it is exhibited that HIRS measurements have better capability in effectively discriminating no-ice/ice cloud information than the AMSU-A or MHS measurements.

\section{Acknowledgements}

The authors acknowledge the NASA CloudSat project. The views expressed here are those of the authors solely and do not constitute a statement of policy, decision, or position on behalf of NOAA, NASA, or the authors' affiliated institutions.

\section{References}

Aires, F., F. Marquisseau, C. Prigent, and G. Sèze. 2011. "A Land and Ocean Microwave Cloud Classification Algorithm Derived from AMSU-A and -B, Trained Using MSG-SEVIRI Infrared and Visible Observations." Monthly Weather Review 139 (8): 2347-2366. doi:10.1175/mwr-d-10-05012.1.

Austin, R. T., A. J. Heymsfield, and G. L. Stephens. 2009. "Retrieval of Ice Cloud Microphysical Parameters Using the Cloudsat Millimeter-Wave Radar and Temperature." Journal of Geophysical Research-Atmospheres 114: 19. doi:10.1029/2008jd010049.

Delanoe, J., R. J. Hogan, R. M. Forbes, A. Bodas-Salcedo, and T. H. M. Stein. 2011. "Evaluation of Ice Cloud Representation in the ECMWF and UK Met Office Models Using Cloudsat and CALIPSO Data." Quarterly Journal of the Royal Meteorological Society 137 (661): 2064-2078. doi:10.1002/qj.882.

Gao, S.-T., X.-F. Li, and Y.-S. Zhou. 2014. "Effects of Water and Ice Clouds on Cloud Microphysical Budget: An Equilibrium Modeling Study.” Chinese Physics B 23 (2): 024204. doi:10.1088/1674-1056/23/2/024204.

He, Q.-J.. 2011. “A Daytime Cloud Detection Algorithm for FY-3A/VIRR Data.” International Journal of Remote Sensing 32 (21): 6811-6822. doi:10.1080/01431161.2010.523730.

Holl, G., S. A. Buehler, B. Rydberg, and C. Jiménez. 2010. "Collocating Satellite-Based Radar and Radiometer Measurements - Methodology and Usage Examples." Atmospheric Measurement Techniques 3 (3): 693-708. doi:10.5194/amt-3-693-2010.

Hutchison, K. D., B. D. Iisager, and R. L. Mahoney. 2013. "Enhanced Snow and Ice Identification with the VIIRS Cloud Mask Algorithm.” Remote Sensing Letters 4 (9): 929-936. doi:10.1080/ 2150704x.2013.815381.

Inoue, T., M. Satoh, Y. Hagihara, H. Miura, and J. Schmetz 2010. "Comparison of High-Level Clouds Represented in a Global Cloud System-Resolving Model with Calipso/Cloudsat and Geostationary Satellite Observations." Journal of Geophysical Research-Atmospheres 115: 15. doi:10.1029/2009jd012371.

Islam, T., M. A. Rico-Ramirez, and D. W. Han. 2012. "Tree-Based Genetic Programming Approach to Infer Microphysical Parameters of the DSDs from the Polarization Diversity Measurements." Computers \& Geosciences 48: 20-30. doi:10.1016/j.cageo.2012.05.028.

Islam, T., M. A. Rico-Ramirez, D. W. Han, M. Bray, and P. K. Srivastava. 2013. "Fuzzy Logic Based Melting Layer Recognition from $3 \mathrm{GHz}$ Dual Polarization Radar: Appraisal with NWP Model and Radio Sounding Observations." Theoretical and Applied Climatology 112 (1-2): 317-338. doi:10.1007/s00704-012-0721-z.

Islam, T., M. A. Rico-Ramirez, D. W. Han, and P. K. Srivastava. 2012. "Artificial Intelligence Techniques for Clutter Identification with Polarimetric Radar Signatures." Atmospheric Research 109-110: 95-113. doi:10.1016/j.atmosres.2012.02.007. 
Islam, T., M. A. Rico-Ramirez, P. K. Srivastava, and Q. Dai. 2014. "Non-Parametric Rain/No Rain Screening Method for Satellite-Borne Passive Microwave Radiometers at 19-85 GHz Channels with the Random Forests Algorithm.” International Journal of Remote Sensing 35 (9): 32543267. doi:10.1080/01431161.2014.903444.

Islam, T., P. K. Srivastava, M. A. Rico-Ramirez, Q. Dai, D. Han, and M. Gupta. 2014. "An Exploratory Investigation of an Adaptive Neuro Fuzzy Inference System (ANFIS) for Estimating Hydrometeors from TRMM/TMI in Synergy with TRMM/PR." Atmospheric Research 145-146: 57-68. doi:10.1016/j.atmosres.2014.03.019.

Jin, Y., S. P. Wang, J. Nachamkin, J. D. Doyle, G. Thompson, L. Grasso, T. Holt, et al. 2014. "The Impact of Ice Phase Cloud Parameterizations on Tropical Cyclone Prediction." Monthly Weather Review 142 (2): 606-625. doi:10.1175/mwr-d-13-00058.1.

Kahn, B. H., F. W. Irion, V. T. Dang, E. M. Manning, S. L. Nasiri, C. M. Naud, J. M. Blaisdell, et al. 2014. "The Atmospheric Infrared Sounder Version 6 Cloud Products." Atmospheric Chemistry and Physics 14 (1): 399-426. doi:10.5194/acp-14-399-2014.

Koop, T. 2013. "Atmospheric Science: The Seeds of Ice in Clouds.” Nature 498 (7454): 302-303. doi:10.1038/nature12256.

Liu, Y. H., S. A. Ackerman, B. C. Maddux, J. R. Key, and R. A. Frey. 2010. "Errors in Cloud Detection over the Arctic Using a Satellite Imager and Implications for Observing Feedback Mechanisms." Journal of Climate 23 (7): 1894-1907. doi:10.1175/2009jcli3386.1.

Millán, L., W. Read, Y. Kasai, A. Lambert, N. Livesey, J. Mendrok, H. Sagawa, T. Sano, M. Shiotani, and D. L. Wu. 2013. "SMILES Ice Cloud Products." Journal of Geophysical Research: Atmospheres 118 (12): 6468-6477. doi:10.1002/jgrd.50322.

Østby, T. I., T. V. Schuler, and S. Westermann. 2014. "Severe Cloud Contamination of MODIS Land Surface Temperatures over an Arctic Ice Cap, Svalbard." Remote Sensing of Environment 142: 95-102. doi:10.1016/j.rse.2013.11.005.

Protat, A., J. Delanoë, P. T. May, J. Haynes, C. Jakob, E. O'Connor, M. Pope, and M. C. Wheeler. 2011. "The Variability of Tropical Ice Cloud Properties as a Function of the Large-Scale Context from Ground-Based Radar-Lidar Observations over Darwin, Australia." Atmospheric Chemistry and Physics 11 (16): 8363-8384. doi:10.5194/acp-11-8363-2011.

Sreerekha, T. R., A. Doherty, and S. English. 2010. "Potential of 229-GHz Channel for Ice-Cloud Screening." IEEE Transactions on Geoscience and Remote Sensing 48 (5): 2183-2188. doi:10.1109/tgrs.2009.2032174.

Srivastava, P. K., D. W. Han, M. A. Rico-Ramirez, D. Al-Shrafany, and T. Islam. 2013. "Data Fusion Techniques for Improving Soil Moisture Deficit Using SMOS Satellite and WRF-NOAH Land Surface Model." Water Resources Management 27 (15): 5069-5087. doi:10.1007/s11269-013-0452-7.

Srivastava, P. K., D. W. Han, M. A. Rico-Ramirez, M. Bray, and T. Islam. 2012. "Selection of Classification Techniques for Land Use/Land Cover Change Investigation." Advances in Space Research 50 (9): 1250-1265. doi:10.1016/j.asr.2012.06.032.

Srivastava, P. K., D. W. Han, M. R. Ramirez, and T. Islam. 2013. "Machine Learning Techniques for Downscaling SMOS Satellite Soil Moisture Using MODIS Land Surface Temperature for Hydrological Application." Water Resources Management 27 (8): 3127-3144. doi:10.1007/ s11269-013-0337-9.

Stein, T. H. M., J. Delanoë, and R. J. Hogan. 2011. "A Comparison among Four Different Retrieval Methods for Ice-Cloud Properties Using Data from CloudSat, CALIPSO, and MODIS." Journal of Applied Meteorology and Climatology 50 (9): 1952-1969. doi:10.1175/2011jamc2646.1.

Stephens, G. L., D. G. Vane, R. J. Boain, G. G. Mace, K. Sassen, Z. E. Wang, A. J. Illingworth, et al. 2002. "The Cloudsat Mission and the A-Train - A New Dimension of Space-Based Observations of Clouds and Precipitation." Bulletin of the American Meteorological Society 83 (12): 1771-1790. doi:10.1175/bams-83-12-1771.

Wind, G., S. Platnick, M. D. King, P. A. Hubanks, M. J. Pavolonis, A. K. Heidinger, P. Yang, and B. A. Baum. 2010. "Multilayer Cloud Detection with the MODIS Near-Infrared Water Vapor Absorption Band." Journal of Applied Meteorology and Climatology 49 (11): 2315-2333. doi:10.1175/2010jamc2364.1.

Yamada, Y., and M. Satoh. 2013. "Response of Ice and Liquid Water Paths of Tropical Cyclones to Global Warming Simulated by a Global Nonhydrostatic Model with Explicit Cloud Microphysics." Journal of Climate 26 (24): 9931-9945. doi:10.1175/jcli-d-13-00182.1.

Yoo, H., and Z. Q. Li. 2012. "Evaluation of Cloud Properties in the NOAA/NCEP Global Forecast System Using Multiple Satellite Products." Climate Dynamics 39 (12): 2769-2787. doi:10.1007/s00382-012-1430-0. 